\title{
Cross sectional echocardiographic appearance in presumed congenital absence of the left pericardium
}

\author{
ISFENDIYAR CANDAN, ÇETIN EROL, AHMET SONEL \\ From the Department of Cardiology, Faculty of Medicine, Ankara University, Ankara, Turkey
}

SUMMARY An unusual and new cross sectional echocardiographic feature, bulging of the inferior left ventricular wall during diastole, is described in a 35 year old woman with congenital total absence of the left pericardium. The diagnosis was made on the characteristic clinical, electrocardiographic, echocardiographic, and radiological findings.

Congenital absence of the left pericardium was thought to be uncommon, and up to about 10 years ago was usually only diagnosed by surgeons and pathologists. The clinical diagnosis from the combination of physical examination, electrocardiogram, and chest radiograph has been reported. ${ }^{12} \mathrm{We}$ present a patient in whom absence of the left pericardium was diagnosed clinically and by cross sectional echocardiography.

\section{Case report}

A 35 year old woman was referred to the cardiology department because of the unusual appearance of a chest radiograph taken before an operation for chronic otitis media. She complained of mild symptoms of atypical chest pain and dyspnoea on exertion for four years. Her blood pressure was 130/80 $\mathrm{mm} \mathrm{Hg}$ and the pulse rate was 80 beats/minute and regular. She was in no distress. The apical impulse was located in the mid axilla and was prominent. There was a grade $1 / 6$ systolic ejection murmur at the pulmonary area. The second heart sound was widely split, but not fixed. The electrocardiogram showed right axis deviation and leftward displacement of the transition zone in the precordial leads. The chest radiograph showed an unusual bulging on the apical area. Left lateral chest radiograph and tomograms showed interposition of lung tissue be-

Requests for reprints to Dr Ahmet Sonel, Cardiology Department, Ibn-i Sina Hospital, Sihhiye-Ankara, Turkey. tween the inferior border of the heart and the left hemidiaphragm (Fig. 1). A similar finding was also shown by a radionuclide perfusion image of the lung. ${ }^{3}$ On $M$ mode echocardiography there was reversed movement of the interventricular septum. Cross sectional echocardiographic examination showed that the dimensions of both ventricles were normal. At the level of the apex beyond the mitral valve (Fig. 2) there was a bulge on the lateral midinferior and inferior walls at the end of diastole and a return to normal during systole. No other abnormal features were seen. The patient did not give her consent for either an artificial pneumothorax or cardiac catheterisation.

\section{Discussion}

Congenital absence of the left pericardium is a rare condition. It may be diagnosed on the basis of clinical signs and electrocardiographic and radiographic findings. The performance of an artificial pneumothorax, to confirm the diagnosis is unwarranted. ${ }^{12}$ Cardiac catheterisation with angiography is useful when the diagnosis is in doubt or when surgical management is necessary, especially for partial absence. ${ }^{12}$ The $M$ mode echocardiographic features of the congenital complete absence of the left pericardium, which are dilatation of the right ventricle and paradoxical interventricular septal motion are not diagnostic of this lesion. They may be seen in various conditions, such as atrial septal defect, partial anomalous pulmonary 


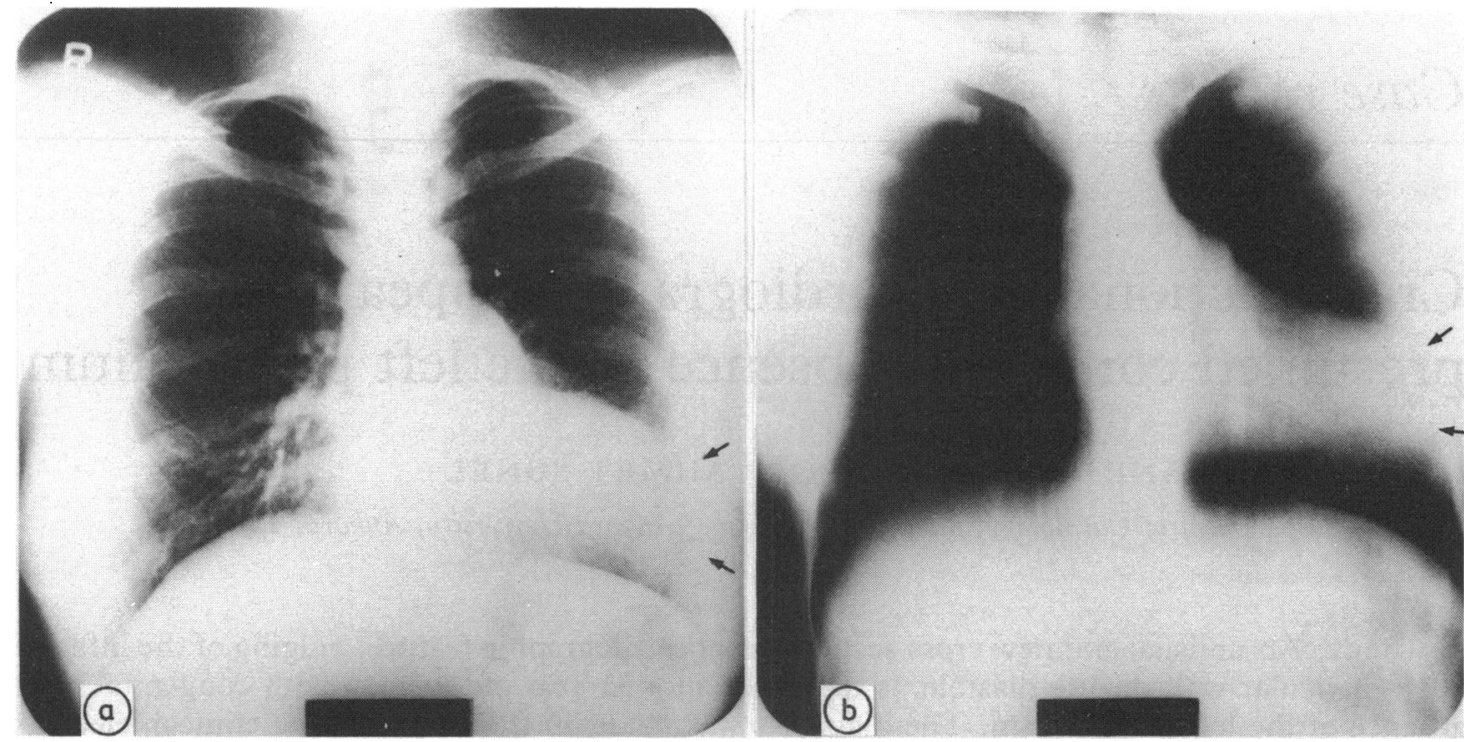

Fig. 1 (a) Chest radiograph and (b) tomogram showing prominent pulmonary artery and the interposition of lung tissue between the inferior border of the heart and the left hemidiaphragm. Unusual bulging of the apical area is indicated by arrows.
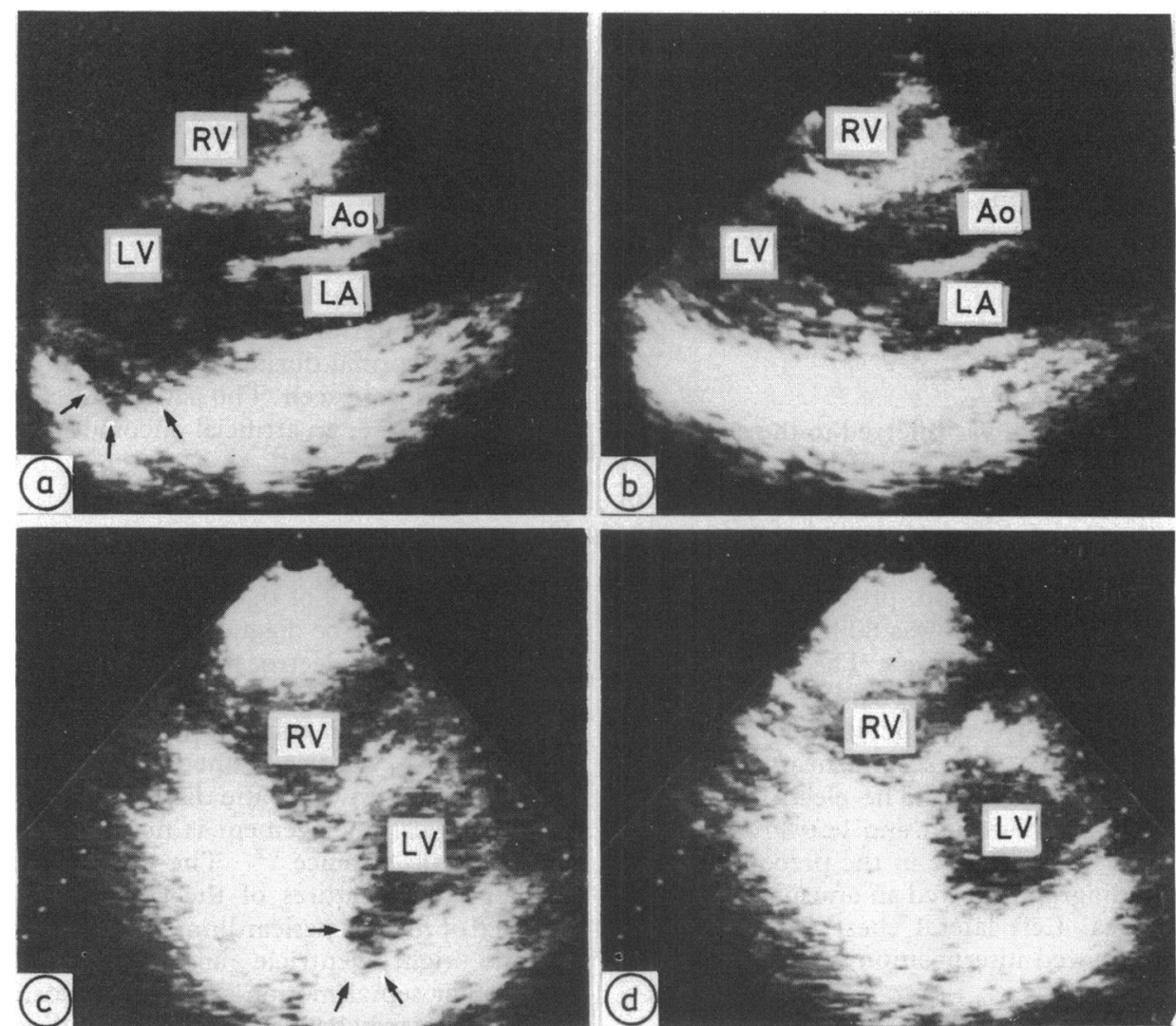

Fig. 2 Echocardiograms in the (a) parasternal long axis view at the end of diastole and (b) the same view at end systole. Note the bulging (arrows) of the lateral inferior wall. (c) Parasternal short axis view at the apex at end diastole and (d) the same view at end systole. Note the same bulging of the inferior wall (arrows). The bulging is not present in (b) and (d). Ao, aorta; LA, left atrium; LV, left ventricle; $R V$, right ventricle. 
venous connection, tricuspid regurgitation, and after cardiac surgery. ${ }^{4}$ None the less, $M$ mode echocardiography is useful for differentiating these conditions when it is used as an adjunct to cross sectional echocardiography. Recently, Rowland et al described the cross sectional echocardiographic findings in a patient with partial absence of the left pericardium. ${ }^{5}$ Nicolosi et al reported cross sectional echocardiographic findings in two patients with absence of the left pericardium. These were caused by lateral rotation and excessive cardiac motion and were consistent with the $M$ mode features. ${ }^{6}$ To our knowledge, this is the first report showing a very unusual feature of a congenital total absence of the left pericardium on cross sectional echocardiography. The bulging seen on the inferior wall may mimic a ventricular aneurysm, but unlike an aneurysm this appearance was most prominent during diastole and disappeared during systole. On the other hand, this localised abnormality of the left ventricular contour with normal right ventricular dimensions can help to distinguish patients with congenital absence of pericardium from those with right ventricular volume overload.
We thank Aytekin Besim and Emin Alp Niron for drawing our attention to this case.

\section{References}

1 Nasser WK, Helman C, Tavel ME, Feigenbaum H, Fisch $\mathrm{C}$. Congenital absence of the left pericardium: clinical, electrocardiographic, radiographic, hemodynamic, and angiographic findings in six cases. Circulation 1970; 41: 469-78.

2 Morgan JR, Rogers AK, Forker AD. Congenital absence of the left pericardium: clinical findings. Ann Intern Med 1971; 74: 370-6.

3 D'Altorio RA, Cano JY. Congenital absence of the left pericardium detected by imaging of the lung: case report. I Nucl Med 1977; 18: 267-8.

4 Payvandi MN, Kerber RE. Echocardiography in congenital and acquired absence of the pericardium: an echocardiographic mimic of right ventricular volume overload. Circulation 1976; 53: 86-92.

5 Rowland TW, Twible EA, Norwood WI, Keane JF. Partial absence of the left pericardium. Am $\mathcal{F}$ Dis Child 1982; 136: 628-30.

6 Nicolosi GL, Borgioni L, Alberti E, et al. M-mode and two-dimensional echocardiography in congenital absence of the pericardium. Chest 1982; 81: 610-3. 